AUdiology

\title{
Cochlear implant in prelingually hearing-impaired adults: prognostic factors and results
}

\author{
L'impianto cocleare nei pazienti adulti con sordità prelinguale: fattori prognostici \\ e risultati
}

\author{
Francesca Forli', Francesco Lazzerini ${ }^{1}$, Valentina Montecchiari ${ }^{1}$, Riccardo Morganti², Luca Bruschini', \\ Stefano Berrettini ${ }^{1,3}$ \\ ${ }^{1}$ Otolaryngology, Audiology and Phoniatrics Unit, University of Pisa, Pisa, Italy; ${ }^{2}$ Section of Statistics, University Hospital of Pisa, \\ Italy; ${ }^{3}$ Department of Clinical Science, Intervention and Technology, Karolinska Institutet, Stockholm, Sweden
}

\section{SUMMARY}

Objectives. The aim of present study is to evaluate the impact of prognostic factors on the outcome in a group of prelingually hearing-impaired patients submitted to cochlear implantation $(\mathrm{CI})$ at an adult age.

Methods. This is a retrospective study on a cohort of prelingually severe-to-profound hearing-impaired patients cochlear implanted in adulthood and followed by a single audiology centre. We correlated post-CI results in term of speech perception with patients' speech perception with hearing aids before implantation, history of progression of hearing loss (HL), and levels of education and cognition. The study group was composed of 49 patients. Results. Post-CI open-set recognition score in silence and noise was significantly correlated with pre-CI open-set recognition score in silence and with background noise. Patients with a history of progression of HL gained significantly better results. Furthermore, we found higher improvements in patients with a higher level of education.

Conclusions. Prelingually deafened patients implanted in adulthood achieved satisfactory results. Significantly better results were achieved by patients with better pre-operative speech perception scores, progressive HL and higher level of education.

KEY WORDS: prelingual deafness, cochlear implant, cognitive aspects, speech perception, educational achievement

\section{RIASSUNTO}

Obiettivo. L'obiettivo di questo studio è valutare l'impatto di alcuni fattori prognostici sui risultati post impianto cocleare in un gruppo di pazienti affetti da sordità prelinguale sottoposti ad impianto cocleare (IC) in età adulta.

Metodi. È stato fatto uno studio retrospettivo su una coorte di pazienti con sordità prelinguale sottoposti a IC e seguiti da un unico centro impianti cocleari, andando ad analizzare $i$ risultati post-impianto in termini di percezione verbale e correlando questi risultati alle capacità di discriminazione verbale pre-impianto, la presenza di una sordità prelinguale ma ad andamento progressivo, i livelli cognitivi e di istruzione.

Risultati. I risultati percettivi post-IC sono stati significativamente correlati con le capacità di percezione verbale pre-IC; inoltre, migliori risultati sono stati ottenuti dai pazienti con una storia di sordità progressiva. Infine, un miglioramento significativamente più cospicuo si è verificato nei pazienti più scolarizzati.

Conclusioni. I pazienti con sordità prelinguale impiantati in età adulta possono raggiungere buoni risultati in termine di percezione verbale. Migliori risultati sono ottenibili nei pazienti con storia di progressione della sordità, buone abilità percettive pre-IC, buon livello di scolarizzazione.

PAROLE CHIAVE: sordità prelinguale, impianto cocleare, aspetti cognitivi, percezione verbale, livelli educativi
Received: September 29, 2020

Accepted: November 27, 2020

\section{Correspondence}

Francesca Forli

ENT Audiology and Phoniatrics Unit, Pisa University Hospital, via Paradisa 2, 56120 Pisa, Italy E-mail: francesca.forli@gmail.com

Funding

None.

Conflict of interest

The Authors declare no conflict of interest.

How to cite this article: Forli F, Lazzerini F, Montecchiari V, et al. Cochlear implant in prelingually hearing-impaired adults: prognostic factors and results. Acta Otorhinolaryngol Ital 2021;41:173-179. https://doi. org/10.14639/0392-100X-N1146

(C) Società Italiana di Otorinolaringoiatria e Chirurgia Cervico-Facciale

\section{c) (1) $(9)$}

This is an open access article distributed in accordance with the CC-BY-NC-ND (Creative Commons Attribution-NonCommercial-NoDerivatives 4.0 International) license. The article can be used by giving appropriate credit and mentioning the license, but only for non-commercial purposes and only in the original version. For further information: https:// creativecommons.org/licenses/by-nc-nd/4.0/deed.en 


\section{Introduction}

Prelingually deafened adult patients who receive a cochlear implant (CI) in adulthood, after many years of severe-toprofound hearing impairment or auditory deprivation, constitute a very specific group of cochlear implant users ${ }^{1-9}$.

Until the mid-1990s, prelingually deafened adult patients were considered poor CI candidates because of limited improvement in speech perception. However, several recent studies suggest that the latest implant technology may result in open-set speech perception abilities and significant subjective benefits, although variability among individuals is high and performance generally lags behind that of postlingually deafened adults $1,2,10$.

Nevertheless, cochlear implantation in prelingually deafened adult patients is still a real challenge, since it requires a difficult decision-making process for both clinicians and patients, due to the uncertainty of the outcome, the risk of obtaining poor or no improvement in speech perception or that they stop using their CI.

In addition, despite significant improvements in average performance after implantation in prelingually deafened adult patients, there remains a considerable amount of unpredictable inter-subject variability. This wide spectrum of results is likely to be related to the wide variability of the characteristics of patients, many of which have a prognostic role.

When considering potential prognostic factors in early hearing-impaired adults, it must be underlined that these patients have some peculiarities since they have never experienced normal hearing in their lifetime, or since the first moments of life. Their neural system, therefore, lacks the spatial and structural organisation for auditory processing with variability between subjects ${ }^{2-6,8,9}$. Furthermore, even if it is possible that auditory pathway fiber tracts develop in a limited degree independently of the experience ${ }^{11}$, the literature suggests that in the case of severe-to-profound prelingual hearing loss, the colonisation of the auditory cortex by other sensory modalities is the main limiting factor in post-implantation performance, and not the pathological degenerative changes of the auditory nerve, cochlear nucleus, or auditory midbrain ${ }^{5,6}$. Both the above-mentioned conditions must be kept in mind when considering the results after implantation achievable by pre-lingually deafened adult patients. Moreover, some recent studies have confirmed the important role of effective early auditory input on CI performance in early deafened adults ${ }^{4-6}$. Consequently, the educational programmes that stress oral communication as the preferred educational modality could potentially reduce the cortical colonisation of the central speech and language processing areas, and therefore the use of oral communica- tion should be an important candidacy criterion in cochlear implantation of adult patients with prelingual deafness ${ }^{1,2,4-6}$. In addition to the factors previously mentioned, it is well known that other pre-operative individual and audiological features play a role in post-operative hearing performance, such as age at onset of hearing loss and at first hearing aid fitting, speech perception performance with hearing aids, residual hearing, communication mode, educational environment, motivation and psychological aspects $2,4,6,9,12,13$. Moreover, in 2011 Dijkhuizen et al. reported that speech intelligibility is predictive of post-implantation hearing results in prelingually deafened adults ${ }^{13,14}$.

From this point of view, improving our knowledge on prognostic factors in this category of patients could help clinicians to predict the results more precisely and allow patients to have realistic expectations.

The aim of the present study is to evaluate the impact of prognostic factors on outcomes in a group of prelingually hearing impaired patients submitted to CI in adulthood at our institution. To do this, we correlated the results achieved in terms of speech perception both in quiet and with background noise with some of the factors that are known to positively affect the post-CI results, such as age at first hearing aid fitting, pure tone audiometry with and without hearing aids before implantation, speech perception with hearing aids before implantation and progression of HL. Furthermore, we investigated the possible correlation between post-CI results with the level of education and cognition of each patient.

\section{Materials and methods}

Since 1998, 75 patients with a prelingual onset of severe to profound hearing loss have received a CI in adulthood at our institution. For the study we enrolled patients with a diagnosis of severe-to-profound hearing deficit and first hearing aid fitting before 4 years of age, who received an oralist rehabilitation during their childhood and who had been consistently using the hearing aid in the implanted ear before surgery, i.e. morning to bedtime, every day.

Among the 75 implanted patients, we enrolled patients who received a unilateral CI in our unit at adult age (16 years or older), who are Italian speakers, had at least 1 year of follow-up in our clinic and who gave their consent to participate in the study. We excluded patients with neuropsychiatric disorders, cochlear malformations, or incomplete electrode array insertion. Forty-nine patients were enrolled according to these criteria.

Local ethical committee approval was obtained.

We retrospectively reviewed the anamnestic data of all patients and audiologic results assessed at the last postopera- 
tive check-up at our centre. Pre-operatively, all patients underwent comprehensive audiological evaluation, including a speech perception test ${ }^{15}$ without lip-reading with hearing aids, neuroradiological evaluation by petrous bone high resolution computed tomography (CT) and brain and inner ear magnetic resonance (MR). The etiology of hearing loss was investigated by molecular analysis of the connexin 26 and 30 genes, and mitochondrial DNA A1555G mutation analysis in all cases, and PDS gene mutation analysis in patients with a large vestibular aqueduct.

Post-operatively, during follow-up visits, all patients were assessed with the CI with pure tone audiometry in free field and with a speech perception test without lip-reading ${ }^{15}$.

Pure-tone audiometry was conducted with an Interacoustics Clinical Audiometer AC40. When measuring the hearing threshold, both with HA and without HA, we assigned a value of $125 \mathrm{~dB}$ to any frequency threshold over the maximum output limit of the audiometer $(105 \mathrm{~dB}$ for $0.25 \mathrm{KHz}$ and $125 \mathrm{~dB}$ for 0.5 and $1 \mathrm{KHz}, 120 \mathrm{~dB}$ for $2 \mathrm{KHz}$ ). Any vibrotactile sensation was excluded.

Speech perception was assessed using a speech perception test in Italian language ${ }^{15}$ before (with HA) and after implantation (with CI) in free field by the same speech therapist in all the patients to avoid bias, with live voice and without lip-reading. We evaluated the disyllabic word recognition score using lists of 20 Italian words at a level of $65 \mathrm{~dB}$. Testing the open-set speech recognition score with background noise, we considered a signal-to-noise ratio $(\mathrm{SNR})+10$. The speech therapist as far as the loudspeaker for the noise stayed in front of the patients during the tests (SONO). Post-operatively, patients that used the CI with a contralateral HA were tested with bimodal stimulation (which is the everyday hearing condition).

At the study setup we administered the "University of Pisa Questionnaire" (UPQ) to all patients to obtain information on personal factors and subjective benefits from CI. This questionnaire was specifically developed by our research team and consists of a 40-question survey divided into 3 sections. In the first, pre-operative information, such as type of hearing aid, ability to have telephone conversations, perception of music and rehabilitation are collected; in the second, the same aspects after implantation are investigated; in the third, information about social life, education level and working life are recorded. The questionnaire is available as supplementary material (Appendix 1 - https:// www.actaitalica.it/article/view/1146/548).

We also evaluated the education level of patients by the UPQ, and divided patients into 3 groups based on each individual level achieved: university degree, a high school certificate and a secondary school certificate.

Furthermore, we submitted patients who gave their consent
(25/49) to a cognitive test, the Raven Standard Progressive Matrices (SPM) ${ }^{16}$. This test has been developed for evaluation of non-verbal, abstract and cognitive functioning and is considered the main test for the estimation of "fluid intelligence" (the ability to reason quickly, think abstractly and problem-solve). Thus, the results are not influenced by educational background or by cultural or linguistic deficiencies.

We correlated the post-CI open-set speech recognition score both in silence and with background noise with the following personal and audiological characteristics of the patients: age at deafness diagnosis and at first HA fitting, presence of pre-operatory progression of hearing loss, preoperatory hearing threshold with and without hearing aids, pre-operatory speech perception score, educational level and results at SPM. Progression was defined as a worsening $>10 \mathrm{~dB}$ in PTA from the diagnosis of HL to pre-operatory evaluation.

For statistical analysis, to compare quantitative variables as post-CI open-set recognition score both in silence and with background noise (dependent variables) with continuous and qualitative variables, Pearson's correlation analysis and t-test for independent samples (two-tailed) were used, respectively. The significant independent variables were then analysed together by a multivariate model based on a multiple linear regression model. Finally, pre-CI openset recognition score in silence and with background noise was compared with post-CI open-set recognition score in silence and with background noise by ANOVA for repeated measures stratified for educational level. Significance was fixed at 0.05 . All analyses were performed by SPSS v. 26 technology.

\section{Results}

We report the results of 49 prelingually deafened patients submitted to CI at adult age at our institution. The characteristics of the cohort are reported in Table I.

Twenty-four patients were women, and 25 were men. The mean age at first HA fitting was 2.1 years (1 month to 4 years). The mean age at the cochlear implantation was 33.9 years (16-60 years).

The mean follow-up duration after surgery was 10.4 years, ranging from 1 to 21 years.

The mean preoperative pure tone threshold in the implanted ear was $107.3 \mathrm{~dB}(87->120 \mathrm{~dB})$ and the mean preoperative free-field threshold with HA was $57.77 \mathrm{~dB}(37-97 \mathrm{~dB})$. The mean preoperative open-set speech recognition score was $14.9 \%(0-75 \%)$ in silence and $0.7 \%(0-15 \%)$ in noise. Only $5 / 49(10.2 \%)$ were capable of sustaining a simple round of telephone conversation with HA preoperatively. 
Table I. Characteristics of the cohort.

\begin{tabular}{|c|c|}
\hline Patients, $n$ & 49 \\
\hline Males, n (\%) & $25(51 \%)$ \\
\hline Use of hearing aids before implantation, $n$ (\%) & $49(100 \%)$ \\
\hline Oral language users, n (\%) & 49 (100\%) \\
\hline Age at diagnosis (years), mean (min-max) & $2,3(0.1-8)$ \\
\hline Age at $\mathrm{Cl}$ (years), mean (min-max) & $33,9(16-60)$ \\
\hline \multicolumn{2}{|l|}{ Progression of hearing loss } \\
\hline Stable, n (\%) & $21(43 \%)$ \\
\hline Progressive, n (\%) & $28(57 \%)$ \\
\hline \multicolumn{2}{|l|}{ Aetiology of hearing loss } \\
\hline Genetic (Connexin 26 or 30 mutations, other), n (\%) & $5(10 \%)$ \\
\hline Large vestibular aqueduct syndrome, n (\%) & $2(4 \%)$ \\
\hline Prenatal infection, n (\%) & $8(16 \%)$ \\
\hline Unknown, n (\%) & $34(69 \%)$ \\
\hline \multicolumn{2}{|l|}{ Educational level } \\
\hline University graduate & $8(16 \%)$ \\
\hline High school certificate & $25(51 \%)$ \\
\hline Secondary school certificate & $16(32 \%)$ \\
\hline
\end{tabular}

In 34 patients, the aetiology of hearing loss was idiopathic (undefined). In 8 patients, hearing loss was related with maternal infections during pregnancy (cytomegalovirus, rubella, toxoplasmosis, parotitis) and in 5 cases with genetic mutations (Connexin 26, Connexin 30, PDS, Chudley-McCulloch syndrome). In 3 cases, the hearing loss was associated with an enlarged vestibular aqueduct (2 nonsyndromic enlarged vestibular aqueduct, 1 Pendred syndrome).

Twenty-eight (57\%) of patients experienced progression of hearing loss, even if to a variable degree.

Eight patients were university graduates, 25 had a high school certificate and 16 a secondary school certificate, according to the UPQ questionnaire. Educational level was not correlated with pre-operative speech perception scores in silence or with background noise $(\mathrm{p}=0.837$ and $\mathrm{p}=0.505$, respectively). The score at SPM ranged from 59 to 16 , with a mean value of 45.84 .

After cochlear implantation, the mean free-field threshold with CI was $38.2 \mathrm{~dB}$ (35-55dB). Postoperative open speech recognition score with CI was $51.7 \%(0-100 \%)$ in silence and $23.1 \%(0-80 \%)$ in noise. Postoperatively, 23 patients (46-9\%) were capable of sustaining a simple round of telephone conversation with CI, even if with variable degrees of performance.

At univariate analysis, post-CI open-set disyllabic recognition score in silence significantly positively correlated with the pre-CI open-set recognition score in silence (Pearson coefficient $=0,477 \mathrm{p}=0,001)$. Post-CI open-set recogni- tion score with background noise, indeed, was found to be significantly positively correlated with the pre-CI open-set recognition score in silence and with background noise (Pearson coefficient $=0,525 ; \mathrm{p}<0.001$ and Pearson coefficient $=0.387 \mathrm{p}<0.01$ respectively). The post-CI open-set disyllabic recognition score in silence and with background noise was not significantly correlated with age at first HA fitting ( $\mathrm{p}=0.302$ and $\mathrm{p}=0.608$ respectively) or pre-CI thresholds with HA ( $\mathrm{p}=0.206$ and $\mathrm{p}=0.319$, respectively) and without HA ( $\mathrm{p}=0.813$ and $\mathrm{p}=0,958$, respectively).

At multivariate analysis, even if the post-CI open-set disyllabic recognition score in silence was confirmed as significantly and positively correlated with the pre-CI open-set recognition score in silence $(\mathrm{RC}=0.632(0.244-1.021)$ $\mathrm{p}=0.002$ ), the post-CI open-set recognition score with background noise, significantly correlated only with the pre-CI open-set recognition score with background noise $(\mathrm{RC}=2.723(0.104-5.344) \mathrm{p}=0.042)$.

Prelingually deafened patients with a history of progression of hearing loss showed significantly better results post$\mathrm{CI}$ open-set speech recognition abilities, both in silence $(\mathrm{p}=0.002)$ and with background noise $(\mathrm{p}=0.007)$. This result was also confirmed with multivariate modelling with multiple linear regression $(\mathrm{RC}=20.9(4.9-37) \mathrm{p}=0.012$ and $\mathrm{RC}=16.2(4.06-28.3) \mathrm{p}=0.010)$.

With ANOVA for repeated measures testing, we observed a significant higher improvement in post-CI speech perception in silence in patients with a university degree $(\mathrm{p}<0.01)$ (Fig. 1). Also, post-implantation speech recognition scores with background noise improved more in patients with a university degree, but the difference between the groups was not statistically significant $(\mathrm{p}=0.310)$.

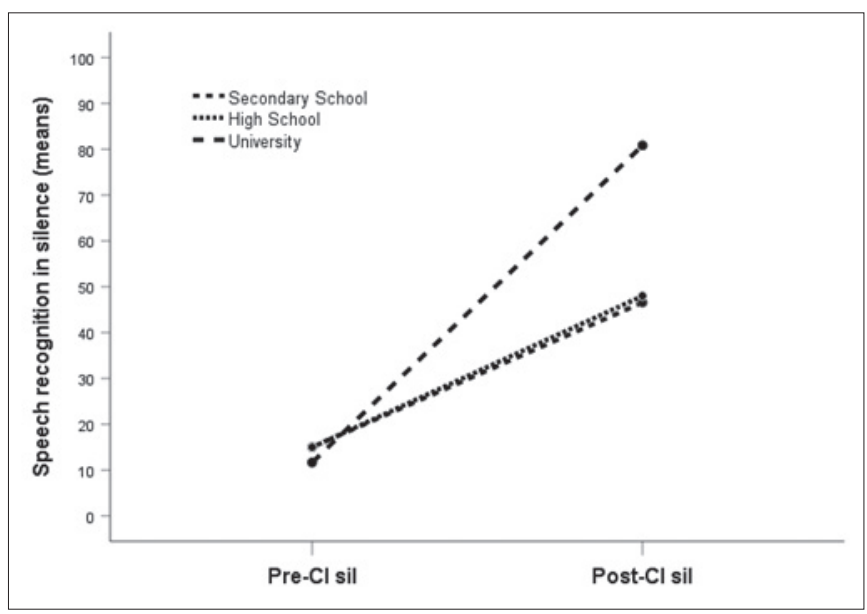

Figure 1. Pre-Cl open-set recognition score in silence compared with post$\mathrm{Cl}$ open-set recognition score in silence by ANOVA for repeated measures stratified for educational level. 
Regarding the correlation between SPM results and postoperative recognition results in silence and in noise, we found a weak positive association but no statistical significance (Pearson coefficient $=0.146 ; \mathrm{p}=0.496$ and Pearson coefficient $=0.076 \mathrm{p}=0.724$, respectively). It must be considered that SPM was administered only to 29 of 49 patients.

\section{Discussion}

The aim of this study was to evaluate the role of prognostic factors affecting the outcome in a group of prelingually deafened patients submitted to CI in adulthood in our Institution. We believe that this study can add knowledge regarding the variability of results seen in early-deafened adult implanted patients and clarify the role of prognostic factors.

Studies in the international literature in this field are limited, and mostly related to heterogeneous samples composed of patients with an exclusive oral communication modality, patients communicating with sign language and patients using total communication $7,10,12,17$. This is a remarkable bias. The educational programmes that stress oral communication as the preferred communication modality, indeed, can potentially reduce cortical colonisation of central speech and language processing centres by other sensorial modalities. Consequently, the use of oral communication since the first years of life should be an important candidacy criterion in cochlear implantation of patients with long-term prelingual deafness, and a fundamental factor underlying the potential for speech perception with a CI ${ }^{4-6}$.

This is one of the few papers that deals this topic reporting on patients using oral communication exclusively. In this regard, it is useful to underline that in Italy, since the 1960s, oralism has been the main rehabilitative choice for patients suffering from preverbal deafness. As a result, in Italy, most adult patients with preverbal hearing impairment seeking a CI received hearing aids at early ages and developed oral language, even if at variable degrees of performance.

The results reported in the literature in early hearing-impaired adult patients implanted in adulthood are usually satisfactory in terms of speech perception and of subjectively perceived benefits, including an improvement in quality of life. In fact, Duchesne et al. ${ }^{3}$ recently reported the post implantation results of 21 prelingually deafened patients; half of participants showed significant improvement in speech recognition performance compared with the pre-implant condition. Moreover, a few participants attained speech recognition levels typically found in adults with postlingual deafness. In the same year, Forli et al. ${ }^{2}$ reported a significant improvement in terms of speech perception and subjective benefits in a group of 30 prelingually deafened implanted adult patients.

The patients in the present study gained significant benefits after implantation, with a mean disyllabic word recognition score of $51.7 \%(0-100 \%)$ in silence and $23.1 \%(0-80 \%)$ in noise.

It is well known that outcomes after $\mathrm{CI}$ in prelingually deafened adults are variable as stressed in the recent investigation by Debruyne et al. ${ }^{12}$. In 27 patients, indeed, the results in terms of open-set word recognition ranged from $0 \%$ to $88 \%$. Similarly, Duchesne et al. ${ }^{3}$ reported a wide variability of speech perception outcomes with recognition scores after implantation ranging from 0 to $95 \%$ and Forli et al. ${ }^{2}$ reported a disyllabic word recognition score ranging from 0 to $100 \%$.

In the present cohort, post-implantation results in terms of disyllabic word recognition score were also variable, ranging from 0 to $100 \%$ in quiet and from 0 to $80 \%$ in noise.

This variability may be related to the wide heterogeneity of patient characteristics. Pre-operative factors that seem to make a significant contribution to post-operative hearing performance are age at onset of hearing loss and at first hearing aid fitting $2,4,13,14$, speech perception performance with hearing aids ${ }^{4-6,8,18}$, residual hearing ${ }^{8}$, communication mode and type of rehabilitation ${ }^{8}$, educational environment ${ }^{8}$, motivation and psychological aspects ${ }^{4-6,8,18}$. Moreover, in 2011 van Dijkhuizen et al. reported that speech intelligibility was a predictor of post-implantation hearing results in a group of prelingually deafened adults ${ }^{13,14}$. More recently, in 2017, in a study on 27 patients Debruyne et al. indicated that postoperative performance in terms of speech perception with CI could be explained to a large extent by two pre-implantation factors: preoperative pure tone audiometry and preoperative consonant-nucleus-consonant (CNC) word test ${ }^{12}$. A recent paper by Ghiselli et al. showed that an early and prolonged auditory stimulation in prelingually deafened cochlear implant recipients may have an important role in determining good post-CI results ${ }^{19}$.

In our sample, some factors indicating good and early acoustic stimulation were correlated with better post-operative speech perception results. In this regard, we found that the pre-operative speech perception with HA and progression of hearing loss before implantation were correlated with good post-implantation results. Both factors indicate some extent of auditory input in the first periods of life. Nevertheless, we could not demonstrate a correlation between speech perception results and age at first hearing aid fitting or pure tone audiometry with HA and without HA before implantation. This finding could be due to the small size of the sample and to the heterogeneity of variables among patients for aspects universally considered to 
play an important role in conditioning post-implantation results, such as degree of hearing loss in the first years of life, or early stimulation with HA. The small and heterogeneous sample of patients make it difficult to understand the exact role of each factor in conditioning the results.

We also correlated educational level with post-implant speech perception. We found significantly higher improvement of open-set speech recognition score in silence after implantation in subjects with a higher level of education. Few other papers have analysed the impact of educational level on post-CI results in terms of speech perception in prelingually severe-to-profound hearing impaired delayed implant patients without finding any significant correlations ${ }^{8,20}$.

We also investigated cognitive function as a possible prognostic factor in late implanted prelingually hearing impaired patients, as is broadly reported in literature that executive functioning and especially working memory are correlated with speech recognition outcomes in CI users ${ }^{21-25}$.

We hypothesised that better cognitive abilities could help patients to better discriminate sounds and language and, in turn, to achieve higher levels of speech perception after implantation. To do this, we submitted our patients to SPM, which is regarded as a culture-fair, non-verbal group test to measure fluid intelligence for diverse populations and requires activation of higher cognitive processes including learning, memory, ability to integrate information and ability to learn a working method. We believe that a non-verbal test, independent of language and reading and writing skills, may be useful for patients with variable degrees of oral language competence, such as those included herein. Other aspects that we considered in choosing the test is the simplicity of use and interpretation. We found a non-significant weak correlation between results at SPM and post-implantation disyllabic word recognition scores in quiet and in noise (Pearson coefficient $=0.129 ; \mathrm{p}=0.549$ in silence and Pearson coefficient $=0.152 \mathrm{p}=0.479$ in noise). The sample may be too small and quite variable for other features affecting the results to establish a possible role of cognitive factors. Zhan et al. ${ }^{26}$ recently analysed this aspect in a cohort of 19 postlingually deafened adult candidates for CI. These patients were evaluated using a visual battery of tests to assess working memory, processing speed, inhibition-concentration and non-verbal reasoning, among which SPM. The authors concluded that in post-lingually adult deafened patients, cognitive factors generally contribute to speech recognition outcomes, but SPM does not correlate with any speech recognition. The present paper confirms this finding concerning the post-CI outcome in pre-lingually hearing impaired patients evaluated with SPM.

\section{Conclusions}

In conclusion, our study offers a further confirmation that prelingually hearing impaired adult patients may achieve significant benefits in speech perception after implantation, even if with a high degree of variability. Among the prognostic factors, indicators of good and early acoustic stimulation are correlated with better post-operative speech perception results. In this regard, we found a significant correlation between pre-operative speech perception scores with hearing aids and post-operative results and between the progression of hearing loss and post-operative results. An effective auditory input in early life may have led the patients' auditory cortex to develop properly, allowing them to gain satisfactory results of speech perception after implantation.

In this special group of patients, cognitive aspects may play a role in achieving good post-operative speech perception skills, but our data do not have statistical significance and further studies and more data on this topic would be useful.

\section{References}

1 Berrettini S, Baggiani A, Bruschini L, et al. Systematic review of the literature on the clinical effectiveness of the cochlear implant procedure in adult patients. Acta Otorhinolaryngol Ital 2011;31:299-310.

2 Forli F, Turchetti G, Giuntini G, et al. Cochlear implant in prelingually deafened oralist adults: speech perception outcomes, subjective benefits and quality of life improvement. Acta Otorhinolaryngol Ital 2017;37:416-422. https://doi.org/10.14639/0392-100X-1493

3 Duchesne L, Millette I, Bherer M, et al. Auditory performance and subjective benefits in adults with congenital or prelinguistic deafness who receive cochlear implants during adulthood. Cochlear Implants Int 2017;18:143-152. https://doi.org/10.1080/14670100.2017.1290925

4 Santarelli R, De Filippi R, Genovese E, et al. Cochlear implantation outcome in prelingually deafened young adults. A speech perception study. Audiol Neurootol 2008;13:257-265. https://doi. org/10.1159/000115435

5 Teoh SW, Pisoni DB, Miyamoto RT. Cochlear implantation in adults with prelingual deafness. Part I. Clinical results. Laryngoscope 2004;114:1536-1540. https://doi.org/10.1097/00005537-20040900000006

6 Teoh SW, Pisoni DB, Miyamoto RT. Cochlear implantation in adults with prelingual deafness. Part II. Underlying constraints that affect audiological outcomes. Laryngoscope 2004;114:1714-1719. https:// doi.org/10.1097/00005537-200410000-00007

7 Waltzman SB, Cohen NL. Implantation of patients with prelingual long-term deafness. Ann Otol Rhinol Laryngol Suppl 1999;177:8487. https://doi.org/10.1177/00034894991080s417

8 Yang WS, Moon IS, Kim HN, et al. Delayed cochlear implantation in adults with prelingual severe-to-profound hearing loss. Otol Neurotol 2011;32:223-228. https://doi.org/10.1097/MAO.0b013e3182040db7

9 Yoshida H, Kanda Y, Miyamoto I, et al. Cochlear implantation on prelingually deafened adults. Auris Nasus Larynx 2008;35:349-352. https://doi.org/10.1016/j.anl.2007.10.003

10 Peasgood A, Brookes N, Graham J. Performance and benefit as outcome measures following cochlear implantation in non-traditional 
adult candidates: a pilot study. Cochlear Implants Int 2003;4:171-190. https://doi.org/10.1179/cim.2003.4.4.171

11 Kral A, Dorman MF, Wilson BS. Neuronal development of hearing and language: cochlear implants and critical periods. Annu Rev Neurosci 2019;42:47-65. https://doi.org/10.1146/annurev-neuro-080317-061513

12 Debruyne J, Janssen M, Brokx J. Late cochlear implantation in early-deafened adults: a detailed analysis of auditory and self-perceived benefits. Audiol Neurootol 2017;22:364-376. https://doi. org/10.1159/000488023

13 van Dijkhuizen JN, Beers M, Boermans PP, et al. Speech intelligibility as a predictor of cochlear implant outcome in prelingually deafened adults. Ear Hear 2011;32:445-458. https://doi.org/10.1097/ AUD.0b013e31820510b7

14 van Dijkhuizen JN, Boermans PP, Briaire JJ, et al. Intelligibility of the patient's speech predicts the likelihood of cochlear implant success in prelingually deaf adults. Ear Hear 2016;37:e302-310. https://doi. org/10.1097/AUD.0000000000000286

15 Burdo S. 1 Care. Protocollo comune di valutazione dei risultati in audiologia riabilitativa. Pisa: C.R.O. Edizioni; 1977.

16 Raven J. Raven: Standard progressive matrices (SPM) Handleiding: Hardcourt Test Publishers; 2006.

17 Debruyne JA, Francart T, Janssen AM, et al. Fitting prelingually deafened adult cochlear implant users based on electrode discrimination performance. Int J Audiol 2017;56:174-185. https://doi.org/10.1080/ 14992027.2016.1243262

18 Kaplan DM, Shipp DB, Chen JM, et al. Early-deafened adult cochlear implant users: assessment of outcomes. J Otolaryngol 2003;32:245249. https://doi.org/10.2310/7070.2003.41601

19 Ghiselli S, Gheller F, Trevisi P, et al. Restoration of auditory net- work after cochlear implant in prelingual deafness: a P300 study using LORETA. Acta Otorhinolaryngol Ital 2020;40:64-71. https://doi. org/10.14639/0392-100X-2316

20 Klop WM, Briaire JJ, Stiggelbout AM, et al. Cochlear implant outcomes and quality of life in adults with prelingual deafness. Laryngoscope 2007;117:1982-1987. https://doi.org/10.1097/ MLG.0b013e31812f56a6

21 Kramer S, Vasil KJ, Adunka OF, et al. Cognitive functions in adult cochlear implant users, cochlear implant candidates, and normalhearing listeners. Laryngoscope Investig Otolaryngol 2018;3:304310. https://doi.org/10.1002/lio2.172

22 Moberly AC, Harris MS, Boyce L, et al. Speech recognition in adults with cochlear implants: the effects of working memory, phonological sensitivity, and aging. J Speech Lang Hear Res 2017;60:1046-1061. https://doi.org/10.1044/2016_JSLHR-H-16-0119

23 Moberly AC, Houston DM, Harris MS, et al. Verbal working memory and inhibition-concentration in adults with cochlear implants. J Speech Lang Hear Res 2017;2:254-261. https://doi.org/10.1002/ lio2.90

24 Moberly AC, Pisoni DB, Harris MS. Visual working memory span in adults with cochlear implants: some preliminary findings. World J Otorhinolaryngol Head Neck Surg 2017;3:224-230. https://doi. org/10.1016/j.wjorl.2017.12.003

25 Moberly AC, Houston DM, Castellanos I. Non-auditory neurocognitive skills contribute to speech recognition in adults with cochlear implants. Laryngoscope Investig Otolaryngol 2016;1:154-162. https:// doi.org/10.1002/lio2.38

26 Zhan KY, Lewis JH, Vasil KJ, et al. Cognitive functions in adults receiving cochlear implants: predictors of speech recognition and changes after implantation. Otol Neurotol 2020;41:e322-e329. https://doi.org/10.1097/MAO.0000000000002544 